\title{
Tin (II) Oxide Nanostructure Thin Film by Thermal Oxidation Technique as LPG Sensor
}

\author{
A.D. Garje*, S.N. Sadakale \\ Department of Physics, Sir Parashurambhau College, Pune - 411 030, Maharashtra, India.
}

\section{ARTICLE DETAILS}

\section{Article history:}

Received 24 June 2017

Accepted 10 July 2017

Available online 21 July 2017

\section{Keywords:}

Thermal Oxidation

$\mathrm{SnO}_{2}$

Thin Film

LPG Sensor

\begin{abstract}
A B S T RAC T
Tin (II) oxide based nanostructure thin films were synthesized using thermal oxidation of pure tin metal on glass substrates. To investigate the effect of thermal oxidation temperature and time on LPG sensing performance of thin films, it was carried at various oxidation temperatures 500, 600, 700, 800, 900 and $1000{ }^{\circ} \mathrm{C}$ with oxidation time of $30,60,90,120,160$ and 190 s respectively. These sensors were tested for $100 \mathrm{ppm}$ concentration of LPG. Thin films synthesized at oxidation temperature of $800{ }^{\circ} \mathrm{C}$ and oxidation time of $120 \mathrm{~s}$ exhibit highest response $\left(\% \mathrm{~S}_{\mathrm{f}}=5 \times 10^{3}\right)$ at operating temperature of $120^{\circ} \mathrm{C}$. The sensors were found to be extremely stable and repeatable with a response and recovery time of 29 and $84 \mathrm{~s}$.
\end{abstract}

\section{Introduction}

The industrial and agricultural growth in the last century causes the side effect of an exponential increase in pollution of the environment on the earth that affects the human health and ecosystems. People, especially in urban areas, are exposed to a high quantity of harmful gases at work, in traffic and at home. Hence there is an urgent need to find solutions that comply with newly reinforced environmental regulations. Many applications, such as an automobile exhaust gas control or air conditioning, as well as household food processing or private diagnosis demand extremely cheap, long-term reliable and analytically powerful gas-sensor devices [1]. Development of gas sensors to monitor combustible gases is imperative due to the concern for safety requirements in homes and industries, particularly for detection of LPG, which is one of the extensively used but potentially hazardous gases, because explosion accident may be caused when it leaks out by mistake. The recent trend shows the effective use of metal oxide nanomaterials due to the possibilities of producing highly active catalysts for sensitive gas sensors. $\mathrm{SnO}_{2}, \mathrm{ZnO}, \mathrm{TiO}_{2}$ are the well-studied materials for gas sensing applications. Therefore there was a search for developing new preparation methods for $\mathrm{SnO}_{2}$ nanomaterials with tailorable phases and to control their surface morphology and size. $\mathrm{SnO}_{2}$ thin films have been fabricated using different techniques by the researchers including dc gas discharge activating reaction evaporation technique [2], electron beam evaporation [3], rf sputtering [4, 5], plasma enhanced chemical vapour deposition [6],hydrothermal [7] and chemical vapour deposition [8] of which yield is small and the processes are time consuming. As evident from literature survey for international/national status, developing the sensor in the form of thin/thick film [9, 10], or pellet [11] is the most practical approach. It is a non-stoichiometric material and the phase of material changes with the method of preparation and type of processing [12]. $\mathrm{SnO}_{2}$ occurs in various phases like tetragonal, orthorhombic, triclinic and cubic etc. The tetragonal phase of $\mathrm{SnO}_{2}$ is the most stable phase amongst the other phases. A thin film of $\mathrm{SnO}_{2}$ with non-stoichiometric nature has high carrier concentration, conductivity and transparency as compared with stoichiometric. This is due to an oxygen vacancy in the structure [13]. The present paper reports LPG sensing properties of $\mathrm{SnO}_{2}$ based thin films with effect of thermal oxidation temperature and oxidation time. The oxidation temperature and time for the synthesis of thin films was optimized.

\section{Experimental Methods}

A quartz tube furnace have been used to evaporate the high purity tin (99.9\%, AR grade, Qualigens, Mumbai, India] on glass substrates with dimensions $2 \times 3 \times 0.1 \mathrm{~cm}^{2}$ under low pressure of about $10^{-4}$ torr. The glass substrate was cleaned with ethanol and distilled water to remove impurities before deposition of film. The tin powder was kept in an alumina boat as a vapour source within the quartz tube furnace. Oxygen gas at atmospheric pressure was bubbled through inlet, at a rate of 400 $\mathrm{cc} / \mathrm{min}$. The substrate was located at a distance of $12 \mathrm{~cm}$ from the evaporated source. The base pressure was achieved by diffusion pump which produces very low pressure of $10^{-4}$ torr .To investigate the effect of oxidation temperature and time deposition was carried out at 500,600, $700,800,900$ and $1000{ }^{\circ} \mathrm{C}$ with oxidation time of $30,60,90,120,160$ and 190 s respectively (refereed as S1, S2, S3, S4, S5 and S6 respectively). Three samples for each oxidation temperature and time was prepared using this technique. Ohmic contacts were fabricated by evaporating 99.999 purity silver wires in an alumina boat. A schematic diagram of quartz tube furnace is introduced in Fig. 1.

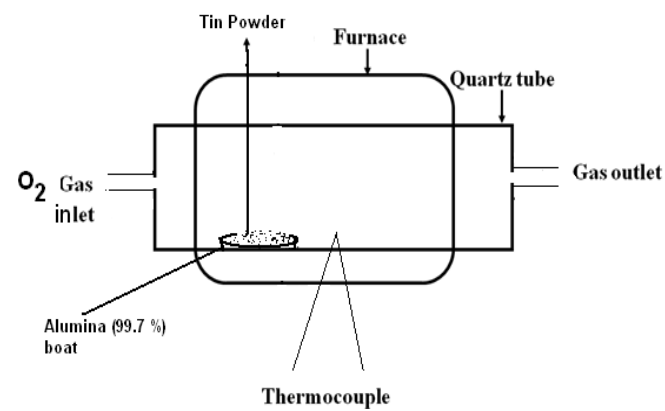

Fig. 1 Quartz tube furnace

\subsection{Structural Characterization}

In structural characterization $\mathrm{X}$ - ray diffraction (XRD), scanning electron micrcrograph (SEM) and thickness measurement of prepared thin films was carried out.

\subsection{XRD Analysis}

$\mathrm{X}$-ray diffraction measurement was done using Philips X-ray generator

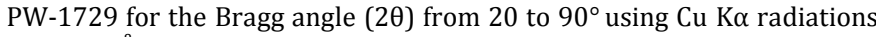
$(\lambda=1.541 \AA)$. The particle size was determined using Scherrer formula, 


$$
D=\frac{0.9 \lambda}{\beta \operatorname{Cos} \theta}
$$

where $D$ is the average crystallite size, $\beta$ is the angular width of the diffraction peak at the half maximum (FWHM) for diffraction angle $2 \theta$.

\subsection{SEM Analysis}

The information about the microstructure and morphology of synthesized thin films was obtained by examining them under scanning electron microscope JOEL JSM 63608.

\subsection{Thickness Measurement}

The weight method was used determine the thickness of the prepared thin films and calculated by using the relation [14],

$$
t=\frac{m}{2 \pi \rho R} \text {. }
$$

Where, $m$ is the mass of the material, $\rho$ is the density of the material, $R$ is the distance between the substrate and the boat.

\subsection{Optical Characterization}

Optical characterization of prepared thin films was executed using double beam Hitachi 330 UV- UV-Visible spectrophotometer in the wavelength range from 200 to $800 \mathrm{~nm}$.

\subsection{LPG Sensor Characterization}

The sensor characterization was accomplished on a static system [15] under laboratory conditions (controlled $40 \% \mathrm{RH}$ ). The temperature of the sensor was varied from $25{ }^{\circ} \mathrm{C}$ to $250{ }^{\circ} \mathrm{C}$ using a resistive heater and measured on a chromel-alumel thermocouple. The sensitivity factor was defined as "S $(\%)=\mathrm{G}_{\text {gas }} / \mathrm{G}_{\text {air }} \mathrm{X} 100$," where $\mathrm{G}_{\text {gas }}$ and $\mathrm{G}_{\text {air }}$ are the conductance of the sensor in the presence and absence of LPG in air, respectively.

\subsection{Response and Recovery Time Measurement}

The response time is defined as the time taken for the sensor to reach from $10 \%$ to $90 \%$ of the saturation value of the sensitivity factor $\left(\mathrm{S}_{\mathrm{f}}\right)$ after the surface has come in contact with the test gas [16] For measuring recovery time, the sensor is exposed to air ambient by maintaining the optimal temperature constant and then time is noted till it achieves at least $90 \%$ of its original value [17].

\subsection{Calibration}

Calibration of LPG sensors was carried out by recording the change in sensitivity at every gas concentration maintained at the optimal temperature of the sensor. The point at which the curve tends to saturate is the maximum limit it can sense.

\subsection{Aging Effect}

Aging effect on the sensors was studied by observing their performance over a period of six months.

\section{Results and Discussion}

\subsection{XRD Analysis of $\mathrm{SnO}_{2}$ Thin Films}

Fig. 2 illustrates the XRD patterns of thermally oxidized $\mathrm{SnO}_{2}$ thin films at different oxidation temperatures and time. As the oxidation temperature increases from 500 to $1000{ }^{\circ} \mathrm{C}$, several sharp and intense peaks appear in the XRD profiles, indicating a high degree of crystallinity. The intensities of the peaks are increasing with increases of oxidation temperature, which can be attributed to the improvement in the crystallinity at higher oxidation temperature. This improvement in the structural order can also be attributed to the increase in the $\mathrm{SnO}_{2}$ film density. It also shows presence of orthorhombic phase of $\mathrm{SnO}_{2}$. Two peaks could be recognized in $\mathrm{S} 1$ is of $\mathrm{Sn}_{2} \mathrm{O}_{3}$ at $27.02^{\circ}$ (JCPDS file no. 25-1259) and $\mathrm{SnO}$ at $34.09^{\circ}$ (JCPDS file no. 24-1342. The coexistence of orthorhombic, tetragonal, and other phases of $\mathrm{SnO}_{2}$ may be attributed to the low oxidation temperature and time of synthesis. With further increase in oxidation temperature and time ( 22 and $\mathrm{S} 3$ ), appearance of orthorhombic phase gradually decreases along with other phases ( $\mathrm{SnO}$ and $\mathrm{Sn}_{2} \mathrm{O}_{3}$ ).

There is increase in intensity of peaks as well as crystalline natures of films are observed. This is in good agreement with the previous reported work [7]. All the diffraction peaks at and above $700{ }^{\circ} \mathrm{C}$ can be readily indexed to tetragonal $\mathrm{SnO}_{2}$. This may be attributed to the increase in the $\mathrm{SnO}_{2}$ film density, which clearly shows the existence of (101) $\mathrm{SnO}_{2}$ peak rather than other peak. The films indicated two strong reflection peaks of tetragonal structure in the orientations of (101) and (200) at $2 \theta=33.89^{\circ}$ and $37.95^{\circ}$, respectively. Dominant peaks at (110), (101) and (211) confirm the cassiterite structure of nanocrystalline $\mathrm{SnO}_{2}$ which is preferred for gas sensing applications. The (110) is the dominant crystal structure of the low index crystal faces for this material due to its stability .Growth of this plane helps in achieving high oxygen vacancy concentrations at low temperatures which is in favour of gas sensing application [14]. The absence of other peaks such as Sn or Sn based oxide at and above $700{ }^{\circ} \mathrm{C}$ indicating the high purity of the samples. The increase in intensity of the peaks with the oxidation temperature can be attributed to the improvement in the crystallinity at higher oxidation temperature [18]. The results of XRD data for S1-S6 are compiled in Table 1. Here the relative presence of different $\mathrm{SnO}_{2}$ phases was derived as follows using a routine procedure for analysis of XRD patterns. First the relative intensities of all observed peaks in a diffractogram were calculated considering the highest peak as with intensity $100 \%$. The normalized intensity of each peak was weighed (multiplied) by the respective fullwidth at half-maximum (FWHM) of the same peak. This represented the area under the peak. Total of such areas in a particular diffractogram was calculated. From this the relative presence of each phase was derived considering all the peaks assigned to that phase [19].The particle size was determined using Scherrer's formula as given in Eq.(1). Table 1 demonstrates the relative presence of different phases of $\mathrm{SnO}_{2}$ at different oxidation temperatures and time.

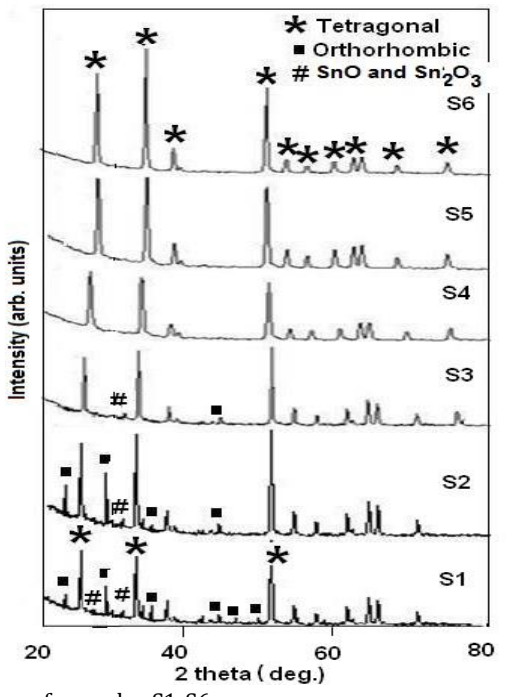

Fig. 2 XRD patteren of samples S1-S6

Table 1 Relative presence of different phases of tin oxide synthesized at different oxidation temperatures

\begin{tabular}{llllll}
\hline Sample & $\begin{array}{l}\text { Tetragonal } \\
(\%)\end{array}$ & $\begin{array}{l}\text { Orthorhombic } \\
(\%)\end{array}$ & $\begin{array}{l}\text { Other } \\
(\%)(\mathrm{SnO}, \\
\left.\mathrm{Sn}_{2} \mathrm{O}_{3}\right)\end{array}$ & $\begin{array}{l}\text { Avg.crystallite } \\
\text { size } \mathrm{D}( \pm 2 \\
\mathrm{nm})\end{array}$ & $\begin{array}{l}\text { Thickness } \\
(\mathrm{nm})\end{array}$ \\
\hline S1 & 53 & 36 & 11 & 40 & 132 \\
S2 & 79 & 13 & 8 & 48 & 136 \\
S3 & 85 & 10 & 5 & 52 & 142 \\
S4 & 100 & - & - & 56 & 148 \\
S5 & 100 & - & - & 72 & 152 \\
S6 & 100 & - & - & 84 & 156 \\
\hline
\end{tabular}

\subsection{SEM Analysis}

A typical SEM for sample S4 is presented in Fig. 3. The average particle size $\sim 62( \pm 2) \mathrm{nm}$ observed in SEM is larger than estimated from X-ray diffraction data indicating agglomeration of the particles. The grains are more in a channelled structure and with increase in size.

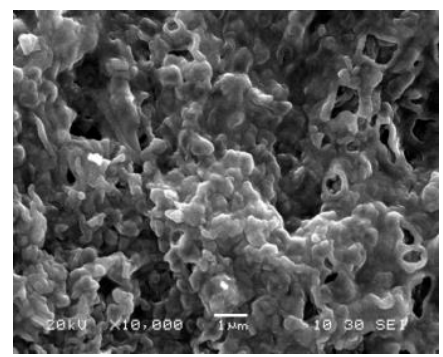

Fig. 3 A typical SEM of sample S4 


\subsection{Optical Characterization}

Fig. 4 depicts a typical UV-Visible spectrograph of sample S4. The peak in the UV absorption is indicative of the band gap of the $\mathrm{SnO}_{2}$ nanoparticles. As the particle size and crystallinity are increased there is a significant red shift in the optical absorption spectra for the samples S5 and S6 (not shown in figure). The shifts of the optical band gap edge towards longer wavelength may be pointed to the decreasing band gap and apparent increase in crystallinity is observed. The optical band gap $\left(E_{g}\right)$ of the S1 was determined by using the formula, $E_{g}=h c / k$, where $h$ is plank's constant, $\mathrm{c}$ is velocity of light, and $\mathrm{k}$ is wavelength. The value of the optical band gap of S4 is $3.62 \mathrm{eV}$ which is almost in agreement with the reported values of band gap by researchers [20].

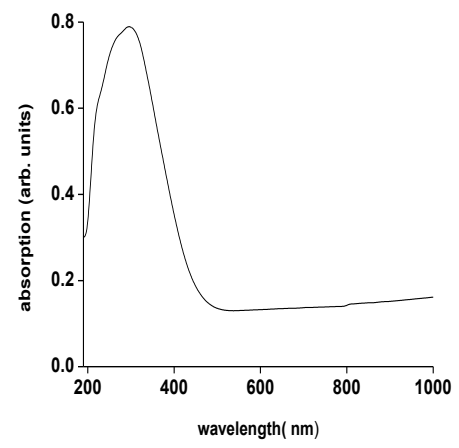

Fig. 4 UV- visible absorption spectrograph of S4

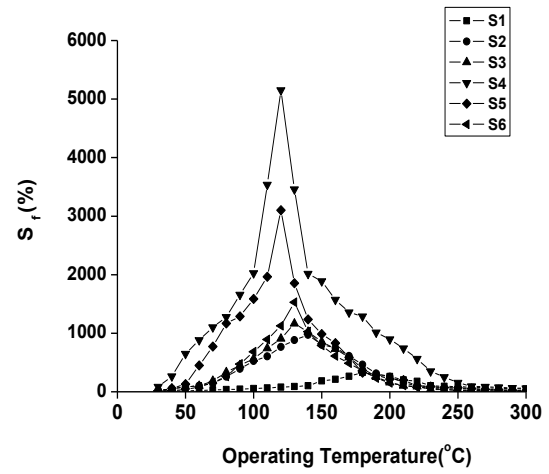

Fig. 5 Sensitivity factor variation with operating temperature

\subsection{LPG Sensor Characterization}

LPG (100 ppm) sensing characteristics of sample S1-S6 are demonstrated in Fig. 5. Initially sensitivity factor increases with operating temperature and reaches to a maximum value at $120{ }^{\circ} \mathrm{C}$ for LPG. This temperature is known as optimal temperature. At the optimal temperature, the activation energy may be enough to complete the chemical reaction (Eq.(3)) which results in the maximum adsorption of the concerned gas and above optimal temperature, the sample temperature increases and it causes the decrease in the sensitivity indicating rate of desorption of the reducing gas (Eq.(5)). LPG is a reducing gas. It reacts with the oxygen ions and releases electrons back to the conduction band, leading to an increase in conductance (a decrease in potential barrier). The larger the depletion region generated in the sensor film, larger is the change in conductance and hence the response. The highest sensitivity factor for sample $\mathrm{S} 4$ is attributed to the dominant presence of tetragonal phase of $\mathrm{SnO}_{2}$. The morphology of the sample $\mathrm{S} 4$ can be considered as the ideal morphology to show good sensitivity because of its channel like structure with neck formations. Many researchers have already discussed the influence of the grain size on sensitivity using grain boundary and neck contacts [21]. The major species contributing on the sensitivity of nanostructured monolithic $\mathrm{SnO}_{2}$ sensor is $\mathrm{O}^{-}$associated with tetragonal phase of $\mathrm{SnO}_{2}$ [18]. In spite of low particle size the poor performance of samples S1-S3 may be attributed to the less relative \% presence of tetragonal phase of $\mathrm{SnO}_{2}$. The $\mathrm{O}_{2}$ - species related to orthorhombic phase do not contribute to sensing properties of the $\mathrm{SnO}_{2}$ [22]. The orthorhombic phase had a detrimental effect on the sensitivity and was attributed to an increased number of planar defects in the microstructure and change in species of oxygen absorbents on the surface layer of the nano- $\mathrm{SnO}_{2}$.The low vale of sensitivity factor in case of samples S5 and S6 would be due to increase in particle size. With increase in oxidation temperature grain diameter increases and causes the low sensitivity towards LPG It is well known that as the grain diameter increases, the surface to volume ratio decreases reducing the adsorption area available for the oxygen and gases and vice versa. The oxidation temperature of $800{ }^{\circ} \mathrm{C}$ and time $120 \mathrm{~s}$ is optimum at which more sites are available for adsorption of gas and hence the highest sensitivity. The variation of sensitivity factor $\left(\mathrm{S}_{\mathrm{f}}\right)$ with oxidation temperature is presented in Fig. 6.

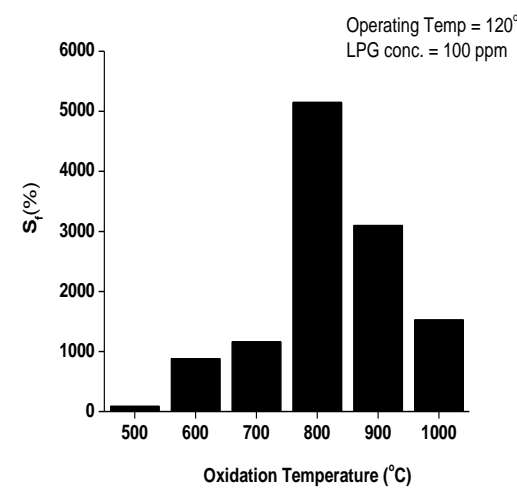

Fig. 6 Sensitivity factor as a function of oxidation temperature

\subsection{Response and Recovery Time}

Fig. 7 displays the response time curve of the sample S4. The response and recovery time of S4 was found to be $29 \mathrm{~s}$ and $84 \mathrm{~s}$ respectively, which is less as compared with earlier reported values [23]. The reaction products do not leave the sensor surface immediately after the reaction, resulting in a longer recovery time.

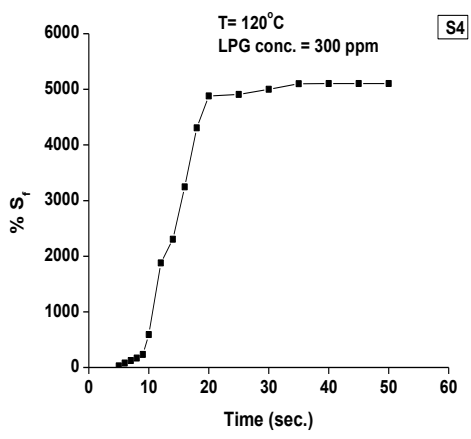

Fig. 7 A typical response time curve for sample S4

\subsection{Calibration of the Sensor}

Calibration of the sensors was carried out by keeping the sensor at the optimal temperature of $120{ }^{\circ} \mathrm{C}$ and the concentration of the gas varied from 10 to $5000 \mathrm{ppm}$. A typical calibration curve for the sample S4 is illustrated in Fig. 8.

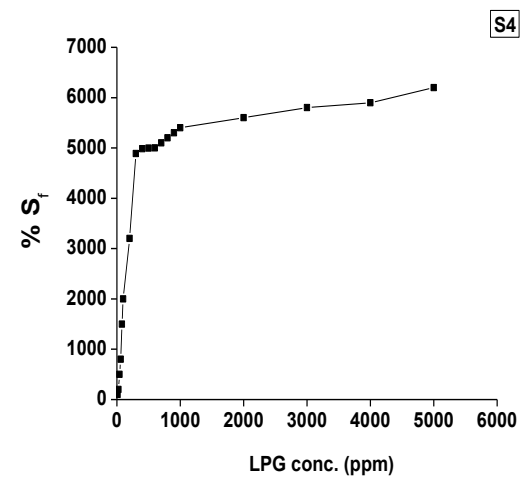

Fig. 8 A typical calibration curve of S4

Three regions were seen in the calibration curve, region I from 10-100 ppm, region II from 100 to $400 \mathrm{ppm}$ and region III $400-5000 \mathrm{ppm}$. The sensitivity factor in region II is higher than region I and III. Similar regions in calibration curve are reported by many researchers in this field [17].

\subsection{Repeatability and Aging Effect}

To check repeatability in the sensor performance, five samples were tested for $100 \mathrm{ppm}$ of LPG. An error bar of $\pm 10{ }^{\circ} \mathrm{C}$ and $\pm 12 \%$ was observed for operating temperature and sensitivity factor respectively. Fig. 9 depicts the sample to sample variations in sensor performance for five 
samples of S4 (one cycle each). Aging studies of the LPG sensors, at optimal temperature of $120^{\circ} \mathrm{C}$ over a period of six months show an initial change of about $\pm 2 \%$ in $S_{f}$ and then stable values for after a period of 25 -30 days.

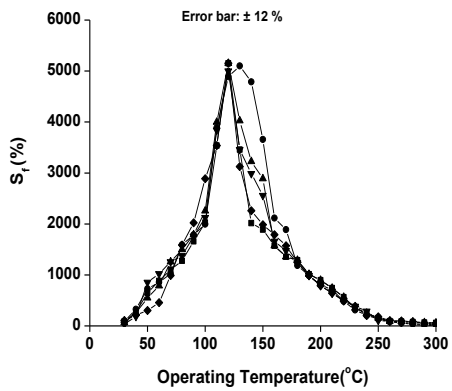

Fig. 9 Repeatability of the sensor S4

\section{Conclusion}

Synthesis of nanocrystalline tin oxide based thin film is carried out using by thermal oxidation technique at various thermal oxidation temperatures. The sensors (S4) synthesized at thermal oxidation temperature of $800{ }^{\circ} \mathrm{C}$ shows better response towards $100 \mathrm{ppm}$ of LPG at $120^{\circ} \mathrm{C}$ with response and recovery time is $\sim 29 \mathrm{~s}$ and $\sim 84 \mathrm{~s}$.

\section{References}

[1] M. Prudenziat, B. Morten, Thick-film sensors: an overview, Sensor Actuator 10 (1986) 65-82

[2] S. Wang, W.Wang, Q. Hu, Y. Qian, Surface modification of tin oxide ultrafine particle thin films, Mater. Res. Bull. 35 (2000) 1235-1241.

[3] S.M. Ayub Durrani, Biasing Voltage dependence of sensitivity of electron beam evaporated SnO2 thin film CO sensor, Sensors 6 (2006) 1153-1160.

[4] M. Di Giulio, SnO2 thin films for gas sensor prepared by R.F. reactive sputtering, Sensor Actuat B-Chem 25 (1995) 465-468.

[5] D. Haridas, A. Chowdhuri, K. Sreenivas, V. Gupta, Enhanced LPG response characteristics of SnO2 thin film based sensors loaded with Pt clusters, Int. J Smart Sens. Intellig. Sys 2-3 (2009) 503-514.

[6] Joshua J. Robbins, Robert T. Alexander, Mailasu Bai, Yen-Jung Huang, Development of tin oxide synthesis by plasma-enhanced chemical vapor deposition, Journal of Vacuum Science \& Technology A: Vacuum, Surf. Films 19 (2001) 2762-2766

[7] M.A.M. Hassan, E.T. Salem, N.J. Mohammed, I.R. Agool, Tin dioxide nanostructure using rapid thermal oxidation method and hydrothermal synthesis of $\mathrm{CuO}-\mathrm{SnO}_{2}-\mathrm{ZnO}$ nano composite oxides, Int. J. Nanosci. Nanoengg. 1 (2014) 22-33.

[8] M. Malekil, S.M. Rozati, An economic CVD technique for pure $\mathrm{SnO}_{2}$ thin films deposition: Temperature effects, Bull. Mater. Sci. 36 (2013) 217-221.

[9] Sberveglieri, Giorgio, Classical and novel techniques for the preparation of SnO2 thin-film gas sensors, Sensor Actuat. B-Chem. 6 (1992) 239-247.

[10] D. Garje Anil, C. Aiyer Rohini, Effect of firing temperature on electrical and gassensing properties of nano- $\mathrm{SnO}_{2}$-based thick-film resistors, Int. J. Appl. Ceramic Technol. 4 (2007) 446-452.

[11] T. Venkata Krishna Karthik, CO gas sensing properties of pure and $\mathrm{Cu}$ incorporated $\mathrm{SnO}_{2}$ nanoparticles: a study of $\mathrm{Cu}$-induced modifications, Sensors 16 (2016) 1283-1286.

[12] S. Vallejos, Chemical vapour deposition of gas sensitive metal oxides, Chemosensors 4 (2016) 4-7.

[13] P.S. Patil, Effect of substrate temperature on structural, electrical and optical properties of sprayed tin oxide $\left(\mathrm{SnO}_{2}\right)$ thin films, Ceramics Int. 29 (2003) 725 734.

[14] Yu, Jiaguo, X. Zhao, Q. Zhao, Effect of surface structure on photocatalytic activity of $\mathrm{TiO}_{2}$ thin films prepared by sol-gel method, Thin solid films 379 (2000) 714.

[15] S.G. Ansari, P. Boroojerdian, S.R. Sainkar, R.N. Karekar, R.C. Aiyer, S.K. Kulkarni, Grain size effects on $\mathrm{H}_{2}$ gas sensitivity of thick film resistor using $\mathrm{SnO}_{2}$ nanoparticles, Thin Solid Films 295 (1997) 271-276.

[16] A. Chowdhuri, Response speed of $\mathrm{SnO}_{2}$-based $\mathrm{H}_{2} \mathrm{~S}$ gas sensors with $\mathrm{CuO}$ nanoparticles, Appl. Phy. Lett. 84 (2004) 7-10.

[17] N.J. Dayan, R.N. Karekar, R.C. Aiyer, Effect of film thickness and curing temperature on the sensitivity of $\mathrm{ZnO}: \mathrm{Sb}$ thick-film hydrogen sensor, J. Mater. Sci. Mater. Elect. 8 (1997) 277-279.

[18] S.K. Tripathy, Tin oxide thin film synthesized by sol-gel and thermal evaporation techniques for gas sensors, Int. J. Sci. Res. 3 (2014) 101-105.

[19] C. Agashe, , A. Garje, R.C. Aiyer, High yield synthesis of nano-crystalline tin dioxide by thermal decomposition for gas sensing applications, Int. J. Appl. Ceram. Technol. 5 (2008) 181-187.

[20] S. Mansoor Ali, Effect of doping on the structural and optical properties of $\mathrm{SnO}_{2}$ thin films fabricated by aerosol assisted chemical vapour deposition, Jour Phys. Conf. Series 439 (2013) 1-4.

[21] S.G. Ansari, Grain size effects on $\mathrm{H}_{2}$ gas sensitivity of thick film resistor using $\mathrm{SnO}_{2}$ nanoparticles, Thin Solid Films 295 (1997) 271-276.

[22] K. Galatsis, p-and n-type Fe-doped $\mathrm{SnO}_{2}$ gas sensors fabricated by the mechanochemical processing technique, Sensor Actuat. B-Chem. 93 (2003) $562-565$.

[23] V.N. Mishra, R.P. Agarwal, Sensitivity, response and recovery time of SnO2 based thick-film sensor array for $\mathrm{H}_{2}, \mathrm{CO}, \mathrm{CH}_{4}$ and LPG, Microelectron. Jour. 29 (1998) 861-874 